\title{
Native and introduced bee abundances on carrot seed crops in New Zealand
}

\author{
B.G. Howlett ${ }^{1}$, G.O. Lankin-Vega ${ }^{2}$ and D.E. Pattemore ${ }^{3}$ \\ ${ }^{1}$ The New Zealand Institute for Plant \& Food Research Limited, Private Bag 4704, Christchurch \\ Mail Centre, Christchurch 8140, New Zealand \\ ${ }^{2}$ Universidad de Chile, Departamento de Sanidad Vegetal, Código Postal 8820808 - La Pintana, \\ Santiago, Chile \\ ${ }^{3}$ The New Zealand Institute of Plant \& Food Research Ltd, Private Bag 3230, Waikato Mail \\ Centre, Hamilton 3240, New Zealand \\ Corresponding author: brad.howlett@plantandfood.co.nz
}

\begin{abstract}
In New Zealand, unmanaged bees species can be important crop pollinators, but their abundance and distribution is poorly known within hybrid carrot seed crops. Standardised counts of bees visiting flowering carrot umbels (1350 umbels observed/field) across 19 commercial hybrid fields were conducted between $1000 \mathrm{~h}$ and $1500 \mathrm{~h}$. Despite honey bees being observed in all fields, abundance varied greatly between fields ( $m e a n=98.1$; maximum $=330$, minimum $=1$ ). Other bees observed visiting umbels were Lasioglossum sordidum (17 fields; mean=14; maximum=65); Leioproctus sp. (12 fields; mean=2.0; maximum=19); Hylaeus sp. (one field; maximum=1) and Bombus terrestris (six fields; mean $=2.0$; maximum $=11$ ). The number of individual bees (all species together) counted/ umbel on male fertile umbels was significantly higher than on male sterile umbels, a factor that could contribute to sub-optimal pollen flow between umbel lines by bees. Examination of their movements between male fertile and sterile lines is required to verify their efficiency as pollinators.
\end{abstract}

Keywords carrot, honey bee, wild pollinators, Bombus, Leioproctus, Lasioglossum, crop pollination, pollinator effectiveness, hybrid crops.

\section{INTRODUCTION}

Honey bee (Apis mellifera Linnaeus, 1758) hives are normally placed in flowering hybrid carrot (Daucus carota L.) fields to pollinate crops. Hybrid carrot seed crops require cross pollination from male fertile to male sterile (female) umbel lines, but honey bees often exhibit a preference for one hybrid line over the other. This behaviour limits pollen transfer and, hence, effective pollination (Erickson \& Peterson 1979). In addition, honey bee abundances between fields may not always be consistent despite their placement at similar densities, because of factors that draw the bees away from the fields, such as nearby competing blooms (Galuszka \& Tegrek 1989). Wild pollinators can complement honey bee pollination by having different flower visitation patterns that increase pollen transfer to stigmas (Artz \& Nault 2011) and by pollinating at different times of the day (Howlett et al. 2013). Moreover, their interactions with honey bees may improve honey bee efficiency by increasing movement between flowers (Brittain et al. 2013). 
Although there are currently only 41 described introduced and native bee species in New Zealand (Donovan 2007), some of these may play an important role in crop pollination (Rader et al. 2009; Davidson et al. 2010; Howlett et al. 2011; Rader et al. 2012; Howlett et al. 2013). There is a lack of published data on the abundance of both honey bee and other wild bee species between and within commercial hybrid carrot seed crops in New Zealand, information that is required to begin assessing their effectiveness as pollinators. Counts of bees (honey and other bee species) visiting standardised numbers of fully flowering male fertile and cytoplasmically male sterile umbels were conducted within 19 fields located across the Canterbury and Central Otago regions in the South Island of New Zealand.

\section{MATERIALS AND METHODS}

The abundance of foraging honey bees and other wild unmanaged bee species was examined within 19 hybrid carrot fields grown across different years. In all but one field, managed honey bee hives had been placed within fields at a density of 6-8 hives per ha. The sampling protocol is described in detail in Howlett et al. (2013), and in this present study, data from these original 14 fields were combined with data from a further five fields surveyed in 2013 and 2014. Surveys consisted of individual bee counts conducted at three different survey times: 1000 to $1100 \mathrm{~h}, 1200$ to $1300 \mathrm{~h}$, and 1400 to 1500 h. These were conducted when fields were at peak flowering (more than $30 \%$ of the umbels contained more than 500 open flowers) and on days where weather was considered suitable for honey bee foraging (temperature $>15^{\circ} \mathrm{C}$, sunny or partly sunny) (Howlett et al. 2013). Three observation areas (radius of $5 \mathrm{~m}$ ) were selected within each field, one each located at opposite field corners ( $5 \mathrm{~m}$ from the field edges) and one in the field centre. At each observation area, counts of bees visiting fully flowering umbels (estimated to contain more than 500 open flowers) were conducted. A total of 150 fully flowering umbels (75 male sterile and 75 male fertile) umbels were examined within each observation area during each sampling time and counts were recorded on paper spreadsheets. At nine fields, the proportions of bees caught on male sterile and male fertile umbels could be analysed to assess whether their distribution may affect the relative propensity of species to cross pollinate. The time taken to complete counts at each observation point for a given survey time was 10-12 min.

Fields examined were located in Central Otago (approximate location: $44^{\circ} 42^{\prime} ; 169^{\circ} 15^{\prime}$; 3 fields grown in 2005) and Canterbury regions (approximate location: $43^{\circ} 44^{\prime} ; 171^{\circ} 43^{\prime} ; 16$ fields: five grown in 2005/6; one in 2006/7; four in $2009 / 10$, one in 2010/11; one in 2013/14 and four in 2014/15).

To assess the relative importance of bee species, year and sampling time in explaining variation in mean bee counts, generalised linear mixed models (GLMM) were fitted with the lmer function in the 'nlme' package (Pinheiro et al. 2014) in programme $\mathrm{R}$ ( $\mathrm{R}$ Core Development Team 2013). A Poison distribution was specified as the data were counts. The site of each sample was included as a random effect term. Terms were dropped stepwise to select the best-supported model based on minimum AIC values. Following the same approach, GLMMs with a Gaussian distribution were used to assess whether the proportion of bees recorded on male sterile lines differed between species, season or sampling time, with site as a random effect.

\section{RESULTS}

\section{Abundances on crops}

In total, 2204 individual bees were observed across all fields (2054 in Canterbury and 150 in Central Otago). Honey bees were the most abundant $(\mathrm{n}=1864)$, followed by Lasioglossum sordidum (Smith, 1853) $(\mathrm{n}=266)$, Leioproctus huakiwi* Donovan, 2007 (*tentatively identified based on captured specimens) $(\mathrm{n}=37)$, Bombus terrestris (Linnaeus, 1758) $(\mathrm{n}=33)$, Leioproctus fulvescens (Smith, 1876) ( $\mathrm{n}=3$ ) and Hylaeus sp. $(n=1)$. Honey bees represented $84.5 \%$ of all bees observed in Canterbury and $86 \%$ of bees in Central Otago fields. Lasioglossum sordidum was the most commonly observed native bee 
in Canterbury (12.5\% of individuals), while in Central Otago it was Leioproctus huakiwi* (5.3\%).

The full model of bee counts, including the factors of bee species, time of day and year, had the best support with all factors significant including the field (Table 1, Figure 1). Although fields were sampled on different days, the weather conditions were very similar, as the days were selected based on fine weather conditions suitable for active foraging (temp. $15.1^{\circ} \mathrm{C}-28.0^{\circ} \mathrm{C}$ ) (Howlett et al. 2013).

The results of the model (Table 1), and the raw bee count data, suggest that the much greater number of honey bees recorded than other species may be driving some of the significant results. The model was re-run after first removing all honey bee data. The best-fitting model without honey bees retained only bee species as a factor, suggesting that there were differences in the counts between non-honey bee species, but that no significant effect of time of day or year could be detected (Figure 2).

From the results of the full model, the low numbers of bees recorded in the 04/05 and 13/14 seemed to be the source of the significance of year. The full model was run again, but the data

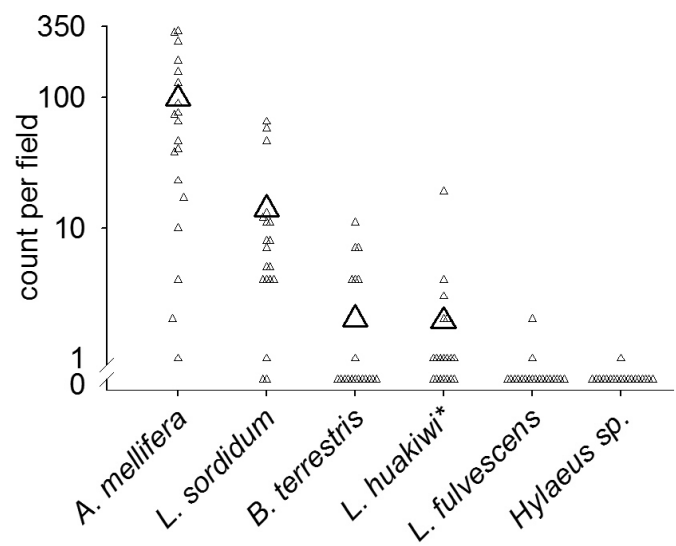

Figure 1 Total counts of individual bees from six species observed between $1000 \mathrm{~h}$ and $1500 \mathrm{~h}$ visiting flowering umbels (1350 umbels observed/ field) within 19 South Island peak flowering hybrid carrot fields. Small triangles are species counts per individual field. Large triangles are mean species counts across fields and years.

from years 2004/05 and 2013/14 was removed. The best-fitting model did not include year, but species and time remained significant, suggesting that the year effect was due to the low counts recorded in these two years.

Table 1 Results of the best-fitting generalised linear mixed model (Poisson distribution), relating counts of bees to the species of bee, time of day and year of survey (fixed effects) in 14 South Island hybrid carrot fields (random effect).

\begin{tabular}{llccrc}
\hline Factor & Variable & Estimate & Std Error & $\mathrm{z}$ value & $\mathrm{P}$ \\
\hline Intercept & (Apis mellifera, 1000 h, 2004/05) & 1.284 & 0.2429 & 5.29 & $<0.001$ \\
\hline Bee species & Bombus terrestris & -3.039 & 0.1675 & -18.14 & $<0.001$ \\
& Hylaeus sp. & -3.867 & 1.0020 & -3.86 & $<0.001$ \\
& Lassioglossum sordidum & -1.678 & 0.0659 & -25.48 & $<0.001$ \\
& Leioproctus fulvescens & -4.163 & 0.5796 & -7.18 & $<0.001$ \\
& Leioproctus huakiwi & -3.035 & 0.1669 & -18.18 & $<0.001$ \\
\hline Time & $1200 \mathrm{~h}$ & 0.833 & 0.0661 & 12.61 & $<0.001$ \\
& 1400 h & 1.196 & 0.0632 & 18.93 & $<0.001$ \\
\hline Year & $2005 / 06$ & 1.641 & 0.6686 & 2.46 & 0.0141 \\
& $2009 / 10$ & 1.424 & 0.3933 & 3.62 & $<0.001$ \\
& $2010 / 11$ & 1.561 & 0.6692 & 2.33 & 0.0197 \\
& $2013 / 14$ & -0.810 & 0.8005 & -1.01 & 0.3116 \\
& $2014 / 15$ & 2.099 & 0.3918 & 5.36 & $<0.001$ \\
\hline
\end{tabular}


Figure 2 Variation over three times of day in the mean number of counts of bees of six different species recorded in South Island carrot fields, averaged over field and year. Error bars are SEM.

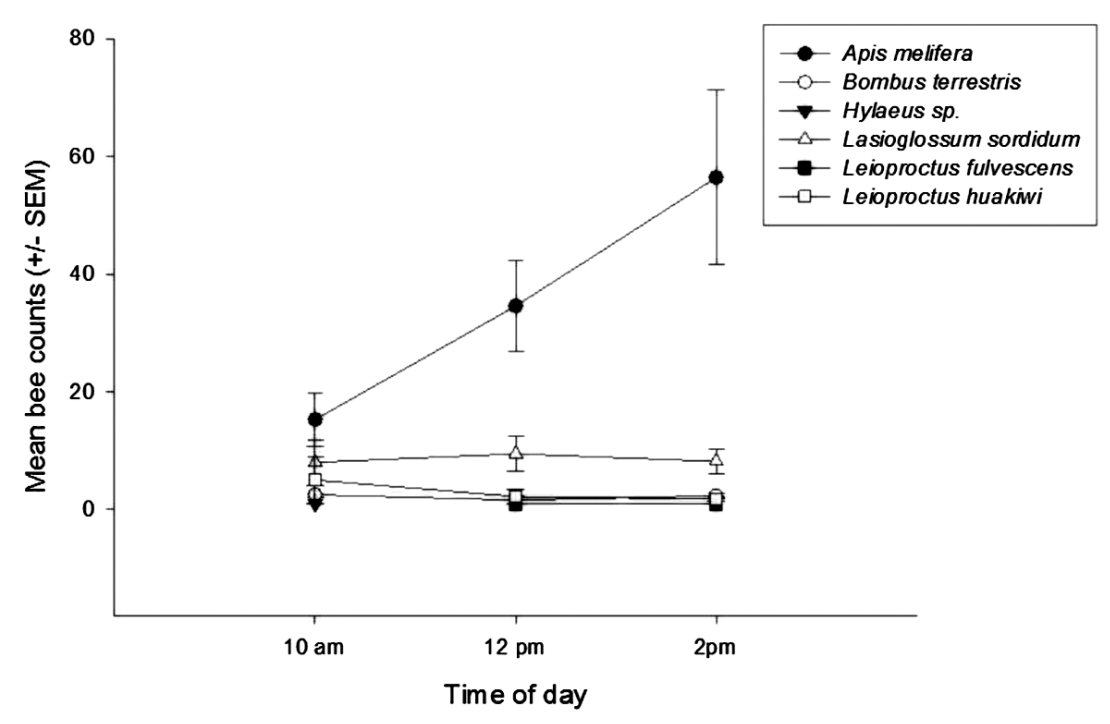

Distribution on male sterile and fertile umbels Overall, more bees were counted on male fertile umbels than on male sterile umbels (two-tailed t-test, $\mathrm{P}=0.0282$ ). This difference was similar for all species apart from Hylaeus sp., where only one individual was counted (Figure 3 ). The bestfitting model for the proportion of bees counted on male sterile umbels included only the random effect term, field. This indicates that there was no significant difference between bee species, time of day or year in the proportions of bees found on male fertile and sterile umbels (Figure 3).

\section{DISCUSSION}

Honey bees are the only managed pollinators readily used for the pollination of broadacre hybrid carrot seed crops. Although a previous study concluded they can be efficient pollinators
Figure 3 Mean counts of bees of five different species on flowering male fertile umbels $(n=675)$ and male sterile umbels $(n=675)$ in South Island carrot fields. Means are averaged over fields, time of day and years.




of open pollinated carrot crops (consisting of just one male fertile variety) (Hawthorn et al. 1960), this may not be the case for hybrid crops where pollinators must move among umbels of male sterile and male fertile plants to transfer pollen. Bees often prefer other flowering plants outside the crop, reducing their potential abundances within both hybrid and open-pollinated carrot fields (Galuszka \& Tegrek 1989). Although not examined, this may be a factor in the large variation of observed honey bee numbers (4-330 individuals) recorded within the 18 hive-stocked fields in this study. New Zealand growers have been reported to apply a standard stocking rate of 8 honey bee hives/ha (T. Cronshaw, The Press, personal communication). The findings of this study suggest a more flexible stocking rate may be a better approach, for example based on direct observation of honey bee activity within fields, as recommended by the Foundation for Arable Research (2012). Notably honey bee hives were lacking in one field in the 2013-14 season, which may explain why just one bee was observed at this field. Apart from the data from this year and the first year, there was no significant difference between years. However, there was considerable variability in counts between fields, suggesting that landscape-level factors may drive relative abundances of bee species on carrot crops in the South Island.

Honey bees showed a strong pattern of increasing activity over the course of the day, and no daily patterns were detected for other species. Although not explored, this may be because of their willingness to exploit a greater variety of floral sources compared to the other bee species. The increased abundance of honey bees on the carrot crop later in the day may indicate that other more favoured sources had been fully exploited first, thus driving greater activity in the less favoured carrot crop later in the day.

A critical factor that determines pollination efficiency in hybrid carrot seed crops is the distribution of foragers between male fertile and sterile lines. Previous studies have reported uneven distributions, with honey bees often favouring umbels with male fertile flowers over those with sterile flowers (Galuszka \& Tegrek 1989). The present study indicated a similar trend with almost all bee species studied. Factors that have been implicated in non-random distribution of honey bees between fertile and sterile lines include differing nectar sugar concentrations (Galuszka \& Tegrek 1989) and floral morphology (Erickson \& Peterson 1979). No difference between bee species was detected in this bias towards male fertile lines, but that may have been caused by the small sample size in this part of the present study. Further research into species differences is warranted, as species that show a less uneven distribution across the lines may contribute significantly more to the pollination of the hybrid seed crops, as long as their distribution is reflected in a willingness for bees to forage across both male fertile and sterile umbels.

However, more even distribution between umbel types does not indicate frequent movements by individual bees between them. Honey bees can exhibit strong floral constancy in hybrid carrot crops, with those foraging on either sterile or fertile umbels rarely moving between them. Erickson et al. (1979) conducted a same day trial ( 85 honey bees observed for 3 min each) and found that $86.5 \%$ of bees on male fertile flowers did not visit male sterile flowers. Likewise, of those visiting male sterile umbels, $81.8 \%$ did not visit the male fertile line. The authors noted continued bee fidelity on male fertile and sterile lines in three subsequent data collections (conducted on additional days in the same trial and additional trials), but with some variability (in one dataset, individual bee fidelity to male fertile umbels was 59.8\%).

Strong floral constancy limits movement of individual bees between hybrid lines and therefore limits pollen flow from male fertile to sterile flowers. Whether this is the case in New Zealand hybrid carrot fields remains to be assessed.

Other non-bee pollinators may also play an important role in pollination (Foundation for Arable Research 2012) and may be worth further assessment. For example, the calliphorid fly Calliphora vicina Robineau-Desvoidy, 1830, is an 
effective pollinator of hybrid carrot crops inside cages (Howlett 2012), while drone flies, Eristalis tenax, Linnaeus 1758, are also considered effective pollinators of carrot (Perez-Banon et al. 2007; Foundation for Arable Research 2012).

In conclusion, this research has found that unmanaged bee species may contribute to the pollination of hybrid carrot crops. However, their unpredictable abundances within and between fields will impact their current effectiveness as pollinators. Further work is required to fully quantify their efficiency, for example, whether the preference to forage on one hybrid line as opposed to the other, is reflected in limited pollen flow to male sterile umbels. For many crops, the presence of other pollinating species alongside honey bees, has been found to generate an additive pollination effect leading to improved crops yields (Garibaldi et al. 2013). The development of strategies to improve yields through better utilisation of managed and unmanaged pollinating species within insect pollinated crops hinge on understanding the current and potential contribution of all pollinating species.

\section{ACKNOWLEDGEMENTS}

The authors thank Melanie Brown, Laura Mesa, Rachael L'helgoualc'h, Alexandre Benoist, Simon Cornut, Lisa Evans and Samantha Read for assisting with data collection. The Foundation for Arable Research supported this research, South Pacific Seeds NZ Limited and Midlands Seed Ltd, and associated growers allowed field access and provided research support. Data used in this publication were collected under the projects MAF-FAR/SFF 05/122, MAF-FAR/SFF 07/035, MBIE C11X1309 and Discovery Science (ID 1465). We acknowledge funding support from Discovery Science (ID 1465).

\section{REFERENCES}

Artz DR, Nault BA 2011. Performance of Apis mellifera, Bombus impatiens, and Peponapis pruinosa (Hymenoptera: Apidae) as pollinators of pumpkin. Journal of Economic Entomology 104(4): 1153-1161.
Brittain C, Williams N, Kremen C, Klein AM 2013. Synergistic effects of non-Apis bees and honey bees for pollination services. Proceedings of the Royal Society B-Biological Sciences 280(1754): 20122767.

Davidson MM, Butler RC, Howlett BG 2010. Apis mellifera and Megachile rotundata: a comparison of behaviour and seed yield in a hybrid carrot seed crop. New Zealand Journal of Crop and Horticultural Science 38: 113-117.

Donovan BJ 2007. Apoidea (Insecta: Hymenoptera). Fauna of New Zealand. Landcare Research Ltd. Christchurch, New Zealand. 295 pp.

Erickson EH, Peterson CE 1979. Problems encountered in the pollination of cytoplasmically male-sterile hybrid carrot seed parents. Proceedings of the Fourth International Symposium on Pollination, Maryland, USA. Pp. 59-63.

Foundation for Arable Research 2012. Crop Pollination, FAR focus, Issue 7. http:// www.far.org.nz/mm_uploads/25801_FAR_ focus_7_-_crop_pollination.pdf (accessed 10 April 2015). 53 pp.

Galuszka H, Tegrek K 1989. Honeybee (Apis mellifera L.) foraging in seed plantations of hybrid carrot (Daucus carota L.). Proceedings of the XXXIst International Congress of Apiculture, Warsaw, Poland, Apimondia Publishing House, Bucharest Romania. Pp. 334-336.

Garibaldi LA, Steffan-Dewenter I, Winfree R, Aizen MA, Bommarco R, Cunningham SA, Kremen C, Carvalheiro LG, Harder LD, Afik $\mathrm{O}$ and others 2013. Wild pollinators enhance fruit set of crops regardless of honey-bee abundance. Science 339: 1608-1611.

Hawthorn LR, Bohart GE, Toole EH, Nye WP, Levin MD 1960. Carrot seed production as affected by insect pollination. Agricultural Experiment Station, Utah State University 422: 1-18.

Howlett BG 2012. Hybrid carrot seed crop pollination by the fly Calliphora vicina (Diptera: Calliphoridae). Journal of Applied Entomology 136: 421-430. 
Howlett BG, Butler RC, Nelson WR, Donovan B 2013. Impact of climate change on crop pollinator activity in New Zealand. MPI Technical Paper No: 2013/30, Ministry for Primary Industries. www.mpi.govt.nz/ document-vault/4101 (accessed 13 April 2015). 45 pp.

Howlett BG, Walker MK, Rader R, Butler RC, Newstrom-Lloyd LE, Teulon DAJ 2011. Can insect body pollen counts be used to estimate pollen deposition on pak choi stigmas? New Zealand Plant Protection 64: 25-31.

Perez-Banon C, Petanidou T, Marcos-Garcia MA 2007. Pollination in small islands by occasional visitors: the case of Daucus carota subsp commutatus (Apiaceae) in the Columbretes archipelago, Spain. Plant Ecology 192(1): 133-151.
Pinheiro J, Bates D, DebRoy S, Sarkar D, R Core Team 2014. nlme: linear and nonlinear mixed effects models. R package version 3.1-117. http://CRAN.R-project.org/package $=$ nlme (accessed 6 April 2015).

Rader R, Howlett BG, Cunningham SA, Westcott DA, Edwards W 2012. Spatial and temporal variation in pollinator effectiveness: do unmanaged insects provide consistent pollination services to mass flowering crops? Journal of Applied Ecology 49(1): 126-134.

Rader R, Howlett BG, Cunningham SA, Westcott DA, Newstrom-Lloyd L, Walker MK, Teulon DAJ, Edwards W 2009. Alternative pollinator taxa are equally efficient, but not as effective as the honeybee in a mass flowering crop. Journal of Applied Ecology 46: 1080-1087. 